\title{
Ecthyma gangrenosum in a pediatric patient and review of the literature
}

\author{
Sevgi Buyukbese Sarsu ${ }^{1 *}$, Mehmet Ergun Parmaksiz ${ }^{1}$, Ayhan Yaman ${ }^{2}$
}

\begin{abstract}
Ecthyma gangrenosum (EG), is an infective lesion of skin, and mucous membranes typically occurring in patients with chronic disease or immunocompromised patients. It is a very rarely seen vasculitis with a potentially progressive and fatal course. An 8-year-old pediatric patient was referred to an external medical center with complaints of fever, abdominal pain, and skin rashes starting 2 days previously, and upon deterioration of his general health state, he was admitted into a surgical intensive care unit with manifestations of septic shock. In the treatment, all necrotic tissues including skin, and subcutaneous tissue were excised down to a healthy tissue after excision of all necrotic tissue. Vacuum assisted closure was applied on this area for drainage. Herein, we aimed to indicate that definitive treatment of a neutropenic child with EG is surgery excision, and also emphasize critical importance of re-excision of newly developed necrotic tissue at an early stage, and close monitorization of the patient.
\end{abstract}

Keywords: Ecthyma gangrenosum, abdomen, neutropenic child

\section{Introduction}

Ecthyma gangrenosum (EG) is an infective lesion characterized by direct involvement of the skin, and mucous membranes by pathogens or hematogenous spread typically seen in patients with chronic or immunosuppressive diseases $(1,2)$. In this very rarely encountered form of vasculitis bacterial dissemination affects adventitia, and media of venous blood vessels of the skin, while intima, and intimal layer, and lumina of these vessels remain intact.

These lesions which are generally seen on the gluteal, and lumbar regions, manifest themselves firstly as painless, red colored macules, and enlarge gradually. They develop into papules, then hemorrhagic bullae, and finally rupture. Grayblack eschar lesion is surrounded by an erythematous halo. EG is very rarely seen in healthy individuals without any risk factor, however, rarely nonbacteremic EG has been also reported (3). Most cases may be associated with septisemia that can increase mortality rate. Herein, we reported the importance of surgical excision as a definitive treatment in a male child with EG.

\section{Case}

An 8-year-old male patient was brought to an external center with complaints of fever, abdominal pain, and rashes persisting for the previous 2 days. Upon deterioration of his health state, he was admitted into intensive care unit with the diagnosis of severe sepsis. Some of his physical examination findings were as follows: body temperature, 390C; heart rate, $150 \mathrm{bpm}$; ABP 70/35 $\mathrm{mmHg}$, and respiratory rate, 44/min. An ulcerated necrotic lesion with regular contours, and dimensions of $10 \times 12$ $\mathrm{cm}$ extending from the right side of the umbilicus on the anterior abdominal wall was seen. This pink colored lesion converted to a black colored eschar with time (Figure 1). Some laboratory parameters of the patient with a history of pneumonia, and recurrent episodes of dental abscess were as follows: white blood cell, $1.270 / \mathrm{mm}^{3}$ UL (4.5-11), neutrophil counts: 260/ $\mathrm{mm}^{3}$, hemoglobin $10.8 \mathrm{~g} / \mathrm{dL}$ (14-18), hematocrit 33.2 (42-52), platelet 806103 (130-400), alanine aminotransferase $158 \mathrm{U} / \mathrm{L}$ (8-60), aspartate aminotransferase $66 \mathrm{U} / \mathrm{L}$ (5-45), creatinine kinase: $4800 \mathrm{ng} / \mathrm{mL}$ (55-170), C-reactive protein $27 \mathrm{ng} / \mathrm{mL}(0$ $0.6)$, mass creatine kinase-MB $101.26 \mathrm{ng} / \mathrm{mL}$ (0-5), troponin I $5.191 \mathrm{ng} / \mathrm{mL}$ (0-0.06), and lactate dehydrogenase $399 \mathrm{U} / \mathrm{L}$ (110-295). On abdominal tomograms a widespread area of necrosis with a diameter of $12 \mathrm{~cm}$ which penetrated deeply into peritoneum was detected (Figure 2). The patient in septic shock was given clindamycin, vancomycin, meropenem, metronidazole, fluconazole, and trimethoprim-sulfametoxazole in addition to inotropic agents. Immunologic tests were

Received: 23-01-2016, Accepted: 22-02-2016

${ }^{1}$ Cengiz Gokcek Obstetrics and Children's Hospital, Clinic of Pediatric Surgery, Gaziantep-Turkey

${ }^{2}$ Cengiz Gokcek Obstetrics and Children's Hospital, Clinic of Pediatric Intensive Care Unit, Gaziantep-Turkey

*Corresponding Author: Sevgi Buyukbese Sarsu E-mail: sarsusevgi@yahoo.com.tr 
requested. Bacterial growth was not detected on blood, and biopsy specimen cultures Neutrophenic patient received granulocyte-colony stimulating factor, and intravenous immune globulin. Treatment: All necrotic tissue under the skin and subcutaneous tissue were excised down to healthy tissue. Then drainage was achieved using vacuum assisted closure (Figure 3). Histopathological evaluation revealed hemorrhagic necrosis,

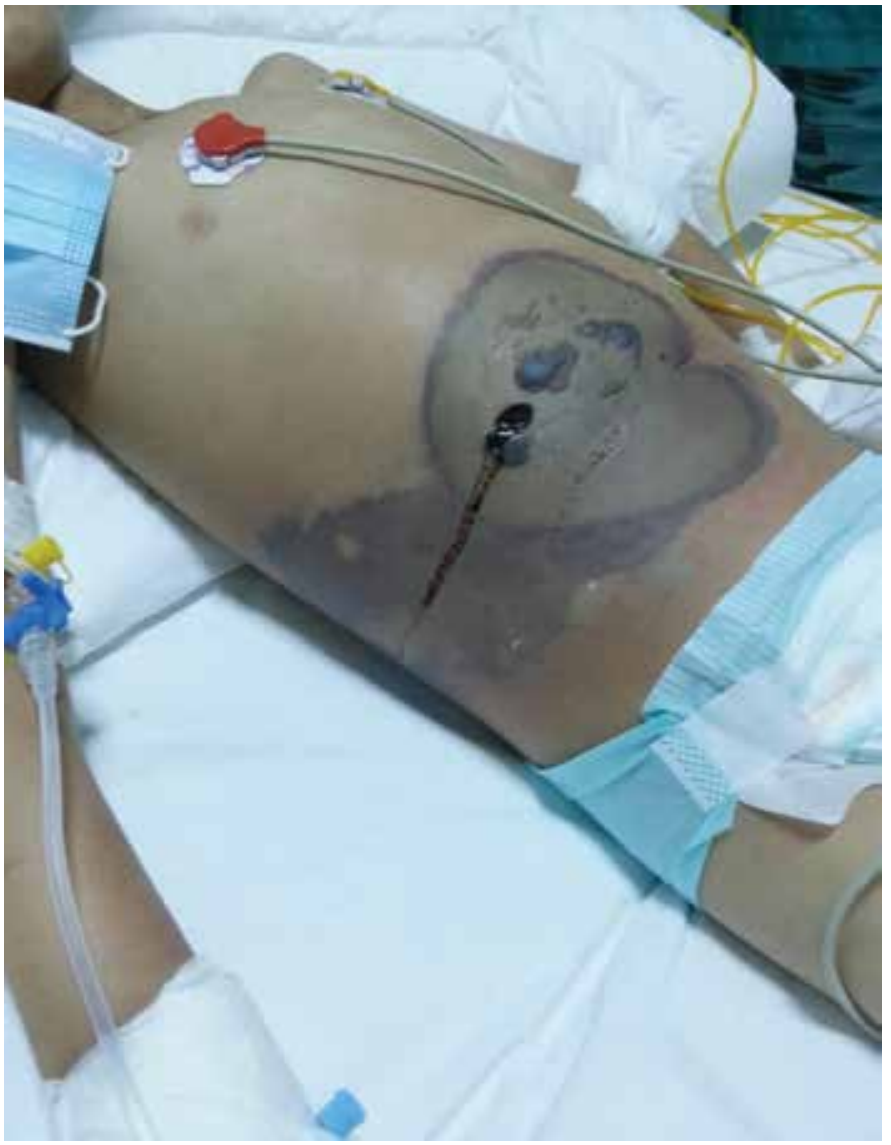

Figure 1. An ulcerated, necrotic lesion measuring $10 \times 12 \mathrm{~cm}$ on the anterior abdominal wall

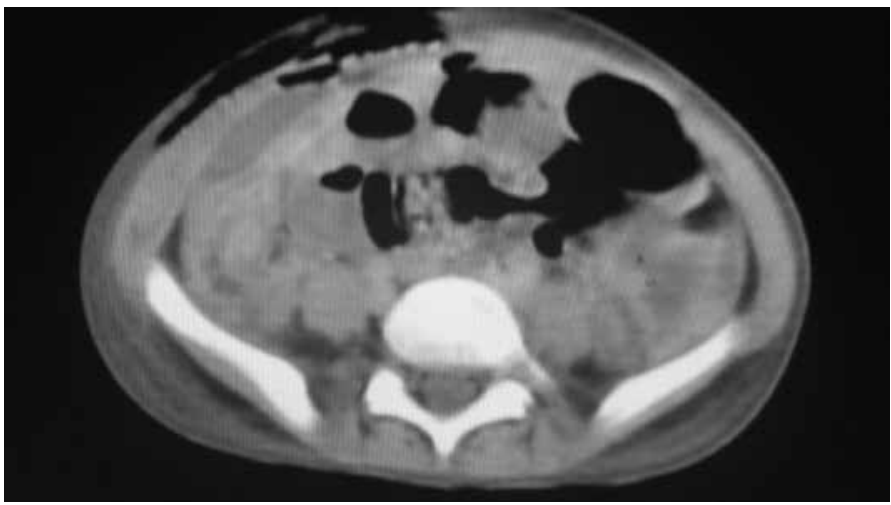

Figure 2. A widespread necrotic lesion with an approximate diameter of $12 \mathrm{~cm}$ penetrating deeply into the peritoneum is observed on abdominal computerized tomography scan

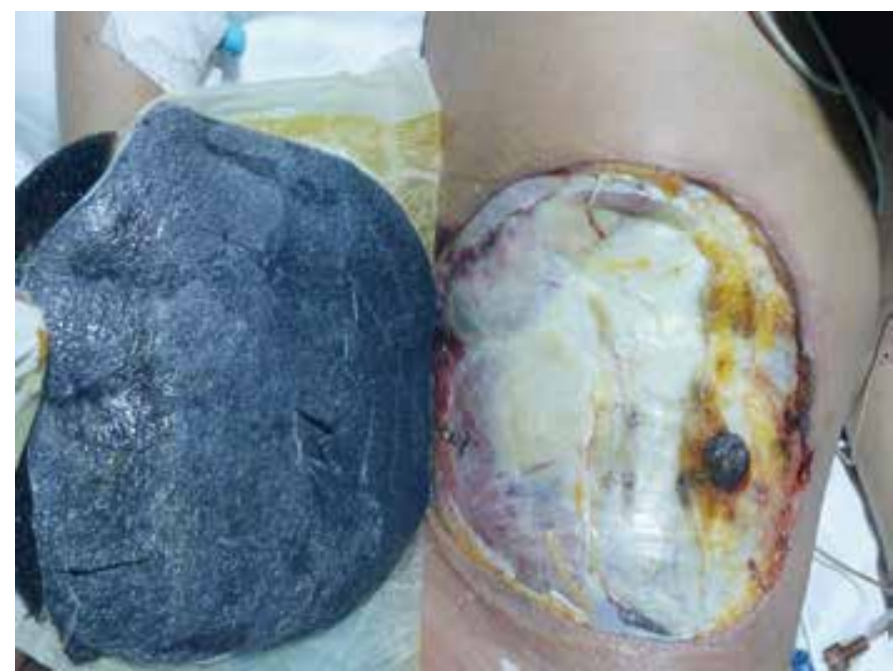

Figure 3. Application of vacuum assisted closure

thrombus formation, inflammatory cell infiltration involving vascular walls, and perivascular space. Newly formed $2 \times 2 \mathrm{~cm}$ necrotic tissues 12 hours later lateral to the excised area were immediately excised. However during follow-up period he had not experienced disease progression or recurrence.

\section{Discussion}

EG is an aggressive cutaneous disease seen mostly in cases with pseudomonas sepsis, and it is characterized by a wide spectrum of skin lesions ranging from maculopapular lesions, hemorrhagic bullae, necrotic tissue to ulcerations (4-7). Lesions can mature within a short time $(12 \mathrm{hr})$ or turn into ulceration with a necrotic center, and manifest different stages of evolution. As was learnt from the anamnesis of our patient, his lesions also followed up the typical stages of development. Lesions generally develop both in cases with or without sepsis This evolution from macule to eschar occurs over a period of approximately 12-24 hours (4). The lesions reportedly are localized on gluteal, and perineal regions, extremities, neck, trunk, and face (8). Mortality rates for EG range from 15\% to as high as $77 \%$ based on reports in the literature (9). Currently, a large local excision, and antibiotherapy are recommended as soon as the diagnosis is established. In the literature, the critical importance of surgeon during the process of definitive diagnosis, and treatment has been emphasized (10). In a neutropenic child with EG should be closely monitored for a possible early intervention in consideration of potential development of new necrotic tissues. Lesions of EG should be rapidly diagnosed by their characteristic morphology so as to avoid complications (11).

\section{Conclusion}

In the definitive treatment of EG timely performed surgical excision has a crucial importance regarding prevention of mortality. 


\section{References}

1. Kryeziu E, Kryeziu K, Bajraktari G, Abazi M, Zylfiu B, Rudhani I, et al. Ecthyma gangrenosum in a patient with acute leukemia. Med Arh. 2010;64:373-374.

2. Fink M, Conrad D, Matthews M, Browning JC. Primary ecthyma gangrenosum as a presenting sign of leukemia in a child. Dermatol Online J. 2012;18:3.

3. Karbuz A, Ozdemir H, Kadıŏlu Şimşek G, Ciftci E, İnce E, Doğru U. Ecythema gangrenosum in a previously healthy child. Turk Arch Ped. 2013;48:68-70.

4. Koo SH, Lee JH, Shin H, Lee JI. Ecthyma gangrenosum in a previously healthy infant. Arch Plast Surg. 2012;39:673 675.

5. Yan W, Li W, Mu C, Wang L. Ecthyma gangrenosum and multiple nodules: Cutaneous manifestations of pseudomonas aeruginosa sepsis in a previously healthy infant. Pediatr Dermatol 2011;28:204 205.
6.

Ozkaya O, Uscetin I, Egemen O, Bingöl D, Akan M. Reconstructive procedure of lower lip defect due to ecthyma gangrenosum: A rare complication of acute lymphoblastic leukemia. J Craniofac Surg. 2012;23:182-184.

7. Gonnelli D, Degardin N, Guidicelli T, Londner J, Magalon G, Bardot J Role of the plastic surgeon in the management of ecthyma gangrenosum in children: Clinical example. Ann Chir Plast Esthet. 2012;57:405-408.

8

Funk E, Ivan D, Gillenwater AM. Ecthyma gangrenosum: An unusual cutaneous manifestation of the head and neck. Arch Otolaryngol Head Neck Surg. 2009;135:818-820.

9. Peña C, Suarez C, Gozalo M, Murillas J, Almirante B, Pomar V, et al Prospective multicenter study of the impact of carbapenem resistance on mortality in Pseudomonas aeruginosa bloodstream infections. Antimicrob Agents Chemother. 2011;56:1265-1272.

10. Jordan DF, Latkowski JA, Louie E, Chiu ES. Diagnosis and management of ecthyma gangrenosum in chronic renal failure patient. Arch Plast Surg. 2014;41:299-301.

11. Bozkurt I, Yuksel EP, Sunbul M. Ecthyma gangrenosum in a previously healthy patient. Indian Dermatol Online J. 2015;6:336-338.

Copyright $($ 2016 The Author(s); This is an open-access article distributed under the terms of the Creative Commons Attribution License (http://creativecommons. org/licenses/by/4.0), which permits unrestricted use, distribution, and reproduction in any medium, provided the original work is properly cited. All Rights reserved by international journal of Medical Science and Discovery. 